\title{
ACOMPANHAMENTO PEDAGÓGICO COM O SOFTWARE MATHCAD \\ PRIME COMO CONTRIBUIÇÃO NA PERSPECTIVA \\ DA APRENDIZAGEM SIGNIFICATIVA
}

\section{PEDAGOGICAL FOLLOW-UP WITH THE MATHCAD PRIME SOFTWARE AS A CONTRIBUTION TO THE PERSPECTIVE OF MEANINGFUL LEARNING}

\author{
Eliani Retzlaff ${ }^{1}$ \\ Rozelaine de Fatima Franzin ${ }^{2}$ \\ Rosangela Ferreira Prestes ${ }^{3}$ \\ Antonio Vanderlei dos Santos ${ }^{4}$
}

\begin{abstract}
Resumo: Existe uma variedade de softwares disponíveis que podem ser usados na Educação Básica e Superior como recursos didáticos para apoiar, reforçar ou complementar as aulas, de forma dinâmica, propiciando situações para uma aprendizagem significativa. $\mathrm{O}$ artigo propõe-se analisar o potencial didático do Software Mathcad Prime como contribuição dessa aprendizagem. Nesse sentido, utilizou-se o Estudo de Funções, pela dificuldade apresentada pelos alunos na compreensão de conceitos, propriedades e análise gráfica, bem como na resolução de problemas. A utilização desse recurso nas atividades dos componentes curriculares de Fundamentos de Matemática "A", Física Geral "A" e Cálculo Diferencial e Integral I, sob a forma de acompanhamento pedagógico, pode favorecer e fortalecer o ensino da Matemática. Os resultados dessa pesquisa mostram que a mediação do software pode promover diferentes abordagens e situações de aprendizagem que envolvem relações conceituais e a utilização de modelos que se ajustam a solução de problemas reais colaborando para o desenvolvimento de estruturas mentais de forma coordenada.
\end{abstract}

Palavras-chave: Aprendizagem significativa; Estudo de Funções; Software Mathcad Prime.

\begin{abstract}
There are a variety of softwares available that can be used in basic and higher education as teaching resources to support, reinforce or complement classes, dynamically strengthening for meaningful learning. The article proposes to analyze the didactic potential of Mathcad Prime Software as a contribution of this learning. In this sense, the Study of Functions was used, due to the difficulty presented by the students in understanding concepts, properties and graphic analysis, as well as in solving problems. The use of this resource in the activities of the curricular components of Fundamentals of Mathematics A, General Physics A and Differential and Integral Calculus I, in the form of pedagogical accompaniment, can support and strengthen the teaching of Mathematics The results of this research show that software mediation can promote different approaches and learning situations that involve conceptual relationships and the use of models that adjust to the solution of real problems collaborating for the development of mental structures in a coordinated way.
\end{abstract}

\footnotetext{
${ }^{1}$ Mestre em Modelagem Matemática pela Unijuí. Professora do Departamento de Ciências Exatas e da Terra. URI - Campus de Santo Ângelo, Brasil. E-mail: elianir@san.uri.br

${ }^{2}$ Doutora em Engenharia de Produção pela UFSC. Professora do programa de Pós-Graduação em Ensino Científico Tecnológico. URI-Campus de Santo Ângelo, Brasil. E-mail: rozelaine@ urisan.tche.br

${ }^{3}$ Doutora em Ensino de Ciências e Matemática pela ULBRA. Professora do Departamento de Ciências Exatas e da Terra. URI-Campus de Santo Ângelo, Brasil. E-mail: ro.fprestes@yahoo.com.br

${ }^{4}$ Doutor em Ciências pela UFRGS. Professor do programa de Pós-Graduação em Ensino Científico Tecnológico. URI-Campus de Santo Ângelo, Brasil. E-mail: vandao@santoangelo.uri.br
} 
Keywords: Meaningful learning; Function Study; Mathcad Prime software.

\section{Introdução}

Das experiências da docência no Departamento de Ciências Exatas e da Terra (DCET) da Universidade Regional Integrada do Alto Uruguai e das Missões (URI), pode-se perceber a prática interdisciplinar por meio de atividades complementares não exclusivas a sala de aula, em que os conhecimentos científicos estudados integram-se entre si, constituindo uma base acerca dos saberes específicos da área de exatas que contemplam os diferentes campos nos quais os acadêmicos vão atuar. Exemplo disso é a experiência do acompanhamento pedagógico proposto aos acadêmicos das disciplinas básicas de Fundamentos de Matemática “A”, Física Geral "A” e Cálculo Diferencial e Integral I, cujo aprendizado e aplicação de conceitos complementares figuram uma prática que transpõe o conteúdo de uma única disciplina.

Essa prática teve como objetivo provocar a mudança de postura do acadêmico, com motivação à aprendizagem significativa ${ }^{3}$, compreendendo-a como processo dinâmico, o qual propõe-se atender necessidades de aprendizagem atuais e futuras dos alunos. Também serve como propósito ao professor de promover o aprendizado com a ressignificação de conceitos matemáticos e aplicação desses, transcendendo o limite da sala de aula. Nessa perspectiva, para ensinar de diferentes formas e permitir distintas dimensões de análise, propôs-se fortalecer essa aprendizagem pelo uso do recurso do software Mathcad Prime.

Nesse contexto, é importante salientar que atualmente há estudos que trabalham com o enlace conceitual entre Física e Matemática. Assim sendo, alguns pesquisadores trabalham com o intuito de saber qual a importância das equações matemáticas no ensino de física (ANJOS et al., 2015), compreendendo, assim, a importância entre conceitos matemáticos envolvidos.

No entanto, um dos principais desafios para o professor do ensino superior está em mostrar ao aluno de forma significativa as conexões entre as leis matemáticas e suas representações. Se assim o fizer, o aluno pode se predispor a relacionar os conceitos da física representados matematicamente, reconstruindo de forma conectada os saberes

\footnotetext{
${ }^{3}$ É o conceito central da teoria proposta pelo psicólogo norte americano, David Paul Ausubel, em 1968 e que foi aprofundada pelo próprio Ausubel et al. (1980).
} 
dessas duas ciências, e ainda, pode evoluir no aprendizado das profissões que necessitem deste tipo de conceitos.

Nessa direção, é possível perceber que ao aliar a área da Matemática e da Física aos novos conceitos envolvidos sobre o uso das novas tecnologias no ensino de Matemática, pode-se criar a possibilidade de adotar diferentes situações e ações didáticas pedagógicas, que tornam possível aprimorar e dinamizar o processo do ensinar e do aprender.

Além disso, salienta Imbernón (2012, p. 19), que a "união das áreas apresentadas ao professor pode fornecer elementos que conduzam ao crescimento intelectual dos aprendizes proporcionando além de ferramenta, uma motivação ao aprendizado significativo", já que para ensinar significativamente necessita-se do interesse em aprender por parte dos acadêmicos. Ao aprender significativamente, eles tornam-se capazes de aplicar os conhecimentos matemáticos, científicos e tecnológicos na construção de saberes específicos nas áreas de engenharias e outras ciências.

Para atender as necessidades referidas, dentre outras práticas educativas, é necessário investigar o processo de aprendizagem dos acadêmicos com o uso do recurso de softwares específicos, bem como analisar os elementos que o compõe como potencializador para a aprendizagem de conceitos matemáticos. Tendo em vista a análise das atividades elaboradas e desenvolvidas com os recursos do software Mathcad Prime, explorou-se o potencial do mesmo no processo de construção de conhecimento, tendo em vista a aprendizagem significativa.

Dessa forma, o presente trabalho aborda o referencial teórico que norteia a pesquisa e embasa a realização dos estudos propostos. Na sequência, apresenta-se a metodologia seguida das atividades de ensino envolvendo conceitos matemáticos aplicados a partir do conteúdo de funções como objeto de estudo, bem como resultados obtidos e conclusões da experiência do acompanhamento pedagógico.

\section{Referencial teórico}

\subsection{Teoria da aprendizagem significativa}

A aprendizagem significativa é o conceito central da teoria proposta pelo psicólogo norte americano David Paul Ausubel, em 1968, e que foi aprofundada pelo próprio Ausubel et al., (1980). É determinada como a aprendizagem que ocorre quando 
as ideias novas estão influenciadas às informações ou conceitos ancorados ao que o aluno

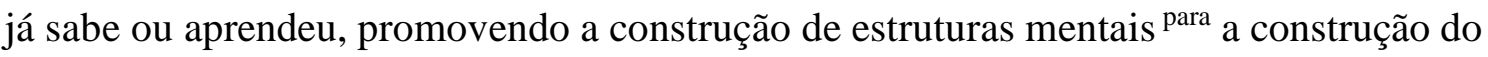
novo conhecimento. $\mathrm{O}$ desenvolvimento dessa proposta também é válido para o ensino superior, pois como em outros níveis, demanda articular o saber prévio dos acadêmicos para utilização na formação de novos conhecimentos e conjecturas, para em seguida relacionar essa aprendizagem com as específicas propostas na grade curricular.

Nesse liame, Moreira (2006) ressalta a ideia que:

Uma vez que significados iniciais são estabelecidos para signos ou símbolos de conceitos, através do processo de formação de conceitos, novas aprendizagens significativas darão significados adicionais a esses signos ou símbolos, e novas relações, entre os conceitos anteriormente adquiridos, serão estabelecidas (MOREIRA, 2006, p. 22).

Com isso, pode-se constatar pela experiência docente no ensino da Matemática, que além dos acadêmicos, muitas vezes os próprios professores demandam compreender novos significados do objeto de estudo. Assim, o planejamento de aulas utilizando-se de material potencialmente significativo, como o software Mathcad para o desenvolvimento de suas práticas pedagógicas, podem servir como um mecanismo para que ocorra a estruturação do conhecimento com significação, apoiando o professor para a melhor compreensão do acadêmico ao mediar o processo de ensino e aprendizagem.

Ausubel (2003) ressalta que para um conteúdo adquirir significado, é importante que haja a associação da nova informação com um conjunto de conhecimentos previamente existentes na estrutura cognitiva do indivíduo. Dessa forma, a ausência de algo já conhecido ou aprendido, sem interagir com conceitos existentes na estrutura cognitiva, promove a aprendizagem mecânica ou repetitiva. Um aliado que poderia ser considerado é o uso de "organizadores prévios", que são materiais introdutórios que antecedem o objeto de estudo a ser aprendido.

O mesmo autor aponta que a estrutura cognitiva tende a ser organizada de forma hierárquica em que conceitos e proposições mais inclusivas com maior poder de generalização ficam no topo da hierarquia. Por isso, sugere-se que na organização do material de ensino se aborde, primeiramente, as ideias mais gerais e inclusivas, seguida da exploração de múltiplas relações para a re/construção de conceitos.

Então, para que ocorra a aprendizagem significativa, segundo Ausubel (2003), o indivíduo deve estar predisposto a aprender e o material a ser assimilado deve ser potencialmente significativo, para que o aprendiz possa interagir os novos 
conhecimentos aos prévios. Tal interação pode ocorrer se o professor simular ações em situações que proporcionem sentido, que transforme ideias, problemas e conceitos em situações do cotidiano em que o aprendiz, por sua vez, possa trazer para si a realidade externa à sua maneira.

Um exemplo pode ser percebido no ensino da Física, que apresenta conceitos abstratos e pouco intuitivos, os quais necessitam de conhecimentos prévios que antecedem o estudo de modelos matemáticos envolvidos em diversos fenômenos. Entre outros elementos, os processos dinâmicos são apresentados de forma estática, sem a possibilidade de fazer relações entre termos de equações e dados reais que envolvem fenômenos físicos, gerando dificuldades de abstração e generalização de conceitos.

Desse modo, para possibilitar consolidar a teoria da aprendizagem significativa segundo Ausubel (2003), é necessário associar práticas de ensino à organização sequencial de objetos de estudo e seu potencial significativo, de forma a produzir assimilação, identificando experiências prévias e estruturas cognitivas já consolidadas.

É importante considerar que para a construção do conhecimento científico por parte do acadêmico, cujo papel ativo, o professor deve acompanhá-lo a fim de gerir a complexidade do objeto de estudo, no intuito de que o mesmo aprenda a pensar e compreender a partir de domínios de conhecimentos básicos. Ao valorizar e utilizar informações e ferramentas, de forma que possam resolver problemas mais complexos que envolvem contextos reais, alicerçam-se e direcionam-se para a futura área de atuação.

Percebe-se, pois, a necessidade de empregar o conhecimento em novas e diversas situações, deflagrando, assim, o ensino de muitas maneiras, múltiplas explicações e dimensões de análise. Para Finque (2003), a aprendizagem implica acima de tudo em um processo de mudança. Nessa direção, aponta-se promover espaços de estudo e investigação que se utilizam de elementos dinâmicos e interativos. Os softwares matemáticos constituem-se de elementos que se mostram como uma possibilidade para auxiliar o professor no desenvolvimento da aprendizagem.

No que segue, tem- se argumentos que justificam a importância da utilização desses recursos, integrados às atividades educacionais com vistas a potencializar a ocorrência de aprendizagem significativa dos acadêmicos.

\subsection{Softwares Matemáticos para o ensino e a aprendizagem a nível superior}


Segundo Costa (2012, p. 31), "as tecnologias digitais são uma ferramenta (cognitiva) do aluno, porque o ajuda, sobre tudo, a pensar e a resolver problemas, mas também a criar e a expressar-se ou a interagir e colaborar com os outros”. Nessa perspectiva, no contexto educacional esses recursos podem promover a interação entre o professor, o acadêmico e o objeto de estudo.

No ambiente acadêmico, o professor, ao apresentar um conteúdo, pode criar condições provenientes de seus saberes (da formação, dos materiais didáticopedagógicos que utiliza da atividade docente), como aponta Tardif (2002), por meio de estratégias de ensino que permitam atividades experimentais, importantes para o estabelecimento de relações mentais, pela investigação, contemplando elementos como experimentação, problematização, análise, entre outros, e posterior construção de significados.

Sob esse aspecto, as tecnologias digitais podem ser entendidas como meios que favorecem o desenvolvimento de habilidades que permitam organizar o pensamento e compartilhar conhecimento. Podem ser compreendidas, ainda, como disparadoras de mudanças no que concerne às relações humanas, podendo, inclusive, influenciar nos processos de aprendizagem. Para Scheid (2017), as tecnologias promovem uma mudança de paradigma educacional, pois alteram a prática educativa, substituindo a escola centrada no ensino centrado em "decoreba" de conteúdos por uma escola centrada nas aprendizagens.

A integração das tecnologias como ferramentas para o ensino e aprendizagem mediada pelo professor pode ser importante a construção do conhecimento pelo próprio acadêmico. No entanto, constata-se que o uso das tecnologias digitais para a aprendizagem pelos alunos ainda está distante do ideal. Um dos aspectos que se mostra como desafio quando se discute a integração de tecnologias ao ensino é o domínio dessas tecnologias pelos professores e ações que podem ser desenvolvidas para que eles possam utilizá-las habilmente.

O fato de utilizar-se de recursos de softwares educacionais para o ensino e aprendizagem da Matemática então, implica no desenvolvimento de novos saberes e uso didático por parte do professor. De forma geral, à priori, é necessário conhecer o recurso, suas funcionalidades para desenvolver, assim, "competências técnicas", como aponta (COSTA, 2012, p. 23). É possível utilizar-se de ferramentas como a própria internet a serviço da exploração e conhecimento desses recursos. Sua usabilidade desses perpassa 
pela relação entre a interface, o conteúdo e as habilidades a serem desenvolvidas, atendendo as expectativas pedagógicas.

Haja vista a necessidade da busca de novos significados para os objetos de estudo a serem desenvolvidos, tanto por acadêmicos quanto por professores, é preciso repensar a forma de abordá-los e decidir sobre o que priorizar, importando-se em auxiliar no processo de exploração, visualização e representação dos conceitos matemáticos e seus contextos. Como hipótese, se essa prática possibilita o desenvolvimento das competências matemáticas, pode ser considerado como um instrumento mediador no processo de ensinar e aprender.

Como exemplo, pode-se perceber a capacidade de aprofundar estudos sobre fenômenos físicos com a utilização de softwares matemáticos, os quais permitem manipulações de variáveis, equações e simulações com programações por meio de linguagens próprias de forma dinâmica. Esses ambientes educacionais proporcionam investigações por meio das diferentes representações sejam elas gráficas, algébricas, geométricas ou numéricas, constituídas a partir da compreensão de conceitos, estabelecimento de relações, métodos e procedimentos matemáticos, tornando possível ampliar e estender conceitos e, também, produzir novos conhecimentos, o que determina o seu uso no ensino superior.

Segundo Costa (2012), esse tipo de conhecimento

[...] que ultrapassa o conhecimento instrumental sobre o funcionamento da ferramenta, permitindo formular hipóteses de trabalho consistentes com os objetivos de aprendizagem visados, é quanto nós decisivo para uma tomada de decisão esclarecida e fundamentada (COSTA, 2012, p. 29).

O reconhecimento do potencial de uma ferramenta, como recurso didático, dá-se na medida em que esse transforma o modo como se aprende, ou seja, quando permite transformar a forma de pensar e agir no processo de construção do conhecimento.

Pela prática pedagógica, pode-se perceber que, independentemente da maneira como o acadêmico aprende ou do conhecimento prévio constituído, ele só conhece um "objeto" se interagir com o mesmo, ao analisar, experimentar, assimilar e abstrair. Nessa perspectiva, o uso de softwares matemáticos pode auxiliar no desenvolvimento desses potenciais cognitivos para a compreensão e absorção do conteúdo lógico-matemático.

Conforme Rodrigues (2009, p. 578), “O sujeito passa a exercer um papel ativo, dialogando, interagindo, elaborando hipóteses e criando soluções para problemas, desenvolvendo, assim, certas capacidades como questionar, refletir e argumentar". Portanto, a utilização de recursos na sala de aula dependendo do objetivo que se quer 
atingir, permite a o aluno construir conhecimento em um processo experimental, facilita a observação e a análise de elementos teóricos, abrangendo um pensar interativo, que vai ao encontro da teoria de Ausubel et al., (1980).

O ambiente simbólico proporcionado pelos softwares matemáticos pode levar os acadêmicos a enxergar os conceitos matemáticos sob perspectivas que desconheciam. Os elementos matemáticos, muitas vezes sob a forma de ícones, possibilitam conexões com as diferentes áreas do conhecimento, o que permite oportunidades de compreensão e utilização de diferentes conceitos. Outras possibilidades estão também relacionadas ao fato de proporcionar ao aluno que trabalhe de modo interativo, aplicando, experimentando, modificando e observando os resultados obtidos através dessas modificações (RETZLAFF et al., 2016).

Em consonância ao exposto, Santos (2010) acrescenta:

\begin{abstract}
A utilização de softwares relacionados ao ensino e aprendizagem deve-se à capacidade de a maioria executar os mais diversos conteúdos matemáticos de forma dinâmica, fazendo com que o aluno enxergue o conteúdo sob diversos ângulos, aguçando seu espírito de observação e de pesquisa: "visam oportunizar a motivação e apropriação do conteúdo estudado em sala de aula" (SANTOS et al., 2010, p.48).
\end{abstract}

Dessa forma, o que antes se tratava de uma matemática estática apresentada em folhas de papel, ganha apoio pela dinamicidade de recursos que podem vir a simular a solução de problemas reais, bem como promover a interação com o outro de forma colaborativa. Como parte de nossa realidade, perpassa então a compreensão e uso desses meios por parte dos educadores e, aos acadêmicos, a identificação da ferramenta como facilitadora na compreensão de conceitos e construção de conhecimento.

\title{
2.3 Estudo sobre funções e o Software Mathcad Prime
}

O estudo de funções contempla seu conceito vinculando-se à linguagem algébrica e gráfica. A natureza algébrica é capaz de expressar a relação entre grandezas que variam, ou seja, uma variável representa os valores do domínio de uma função, chamada variável independente, da qual dependem outros números, denominada variável dependente.

As representações na forma de tabelas, gráficos, regras matemáticas e modelos favorecem a compreensão do conceito de funções, bem como na resolução de situações problemas. Especialmente a representação em forma de gráficos facilita a observação de comportamentos. Neles, pode-se perceber o domínio, o contradomínio e a regra de correspondência, simultaneamente, bem como avaliar o comportamento de fenômenos da 
natureza.

O estudo das funções permite ao aluno adquirir a linguagem algébrica como a linguagem das ciências, necessária para expressar a relação entre grandezas e modelar situações-problema, construindo modelos descritivos de fenômenos e permitindo várias conexões dentro e fora da própria matemática (BRASIL, 2006, p.121).

Tendo em vista as potencialidades mencionadas anteriormente, propõe-se nesse trabalho a utilização do software Mathcad Prime ${ }^{4}$. Esse Software é baseado em Álgebra computacional, o qual permite a entrada e manipulação de equações matemáticas, realização de cálculos, análise de dados e geração de gráficos, elementos importantes a realização de tarefas que envolve a matemática e o desenvolvimento de projetos.

Por integrar textos à matemática e a gráficos num único ambiente, pode-se resolver e documentar cálculos ou mesmo desenvolver projetos. Com a matemática simbólica e a matemática numérica integrada os cálculos podem ser produzidos, reproduzidos, compartilhados e reutilizados. Os exemplos práticos envolvendo questões referentes à aritmética, álgebra e gráfica e ao gerenciamento inteligente de unidades expressa em notação matemática padrão, e, seus itens de menu contendo várias funcionalidades, colaboram para um ambiente educacional de grande potencial para significação. Na interface do programa, pode ser percebida na Fig.1 a semelhança com um processador de textos.

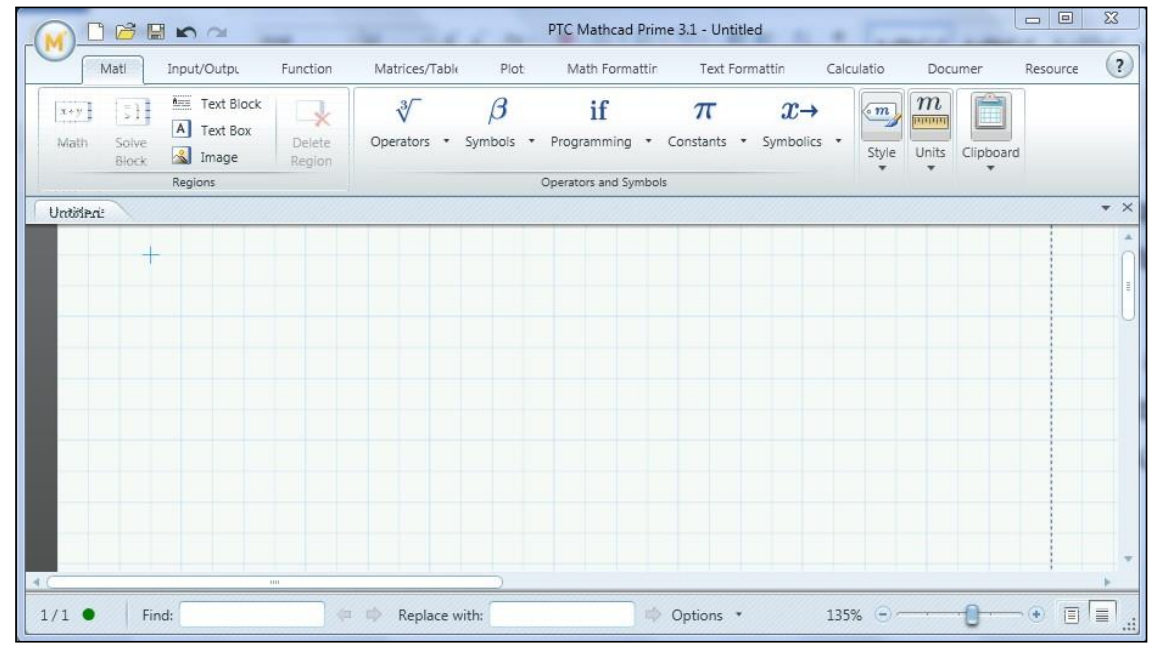

Figura 1: Interface Mathcad Prime 3.1

Fonte: Mathcad Prime 3.1

O software mathcad permite processar as informações de forma explícita em sua interface. Com as vantagens em seu sistema de manipulação algébrica, numérica e gráfica, o acadêmico pode pensar de forma mais conceitual e menos mecânica, elementos

\footnotetext{
${ }^{4}$ É um software destinado principalmente à verificação, validação, documentação e reutilização de cálculos de engenharia, não sendo livre. PTC Mathcad-PTC (2009).
} 
esses que podem colaborar para transformar tais informações em conhecimento.

\section{Metodologia}

A pesquisa busca a solução para um problema ou dificuldade na qual os participantes da pesquisa estão envolvidos. Desta forma, parte-se da contextualização da pesquisa para a elaboração de uma sequência de atividades que se utiliza de software matemático para a ressignificação/reconstrução de conceitos matemáticos, abordando-se, em seguida, elementos importantes desses ambientes aos quais se objetiva concluir experiências para a construção de conhecimento científico.

Dessa forma, a proposta estabeleceu o acompanhamento pedagógico de um grupo de 20 alunos de semestres diferentes, matriculados nos cursos de Engenharias e Matemática de uma instituição comunitária. Como forma de motivação à carreira docente, propôs-se a uma aluna da graduação a experiência em atividades técnicas, didáticas e científicas, em que ela atuasse como docente Júnior para o acompanhamento pedagógico. Nesse processo, foram definidas datas de reuniões mensais para acompanhamento dos acadêmicos e preenchidas fichas de relatório, material este que ficou arquivado em pasta para avaliação da ação e para certificação final de participação. As atividades desenvolvidas dividiram-se em 32 horas mensais (totalizando 3 meses) entre planejamento e atendimento aos alunos.

Os encontros da discente e pesquisadores com os professores das disciplinas de Fundamentos de Matemática "A", Cálculo Diferencial e Integral I e Física Geral "A", possibilitaram o contato com o conteúdo e a metodologia utilizada, iniciando-se nesse momento os estudos e, posteriormente, o planejamento das aulas. Das 8 horas semanais propostas, 4 horas foram disponibilizadas para estudo e planejamento e 4 horas para o acompanhamento aos acadêmicos.

No início das atividades, optou-se por identificar o que efetivamente os acadêmicos conheciam sobre o assunto a ser abordado, seu conhecimento prévio. Esse processo deu-se a partir da sondagem por meio de situações problemas elaborados peles pesquisadores e docente júnior. Pelas falas dos envolvidos pode-se verificar a forma de abordagem do cálculo, da física e suas aplicações, utilizando comparações, classificações, relações, entre outros elementos. Diante do exposto, foram propostas atividades com objetivo de que compreendessem seus limites e capacidade de raciocínio, pela elaboração de novas estruturas mentais pelo tratamento de informações e representação de situações 
em ambiente específico do software Mathcad Prime, para o ensino e a aprendizagem.

Em seguida, foram elaboradas situações problemas, como as descritas no decorrer do material apresentado, baseadas em questionamentos e discussões entre os professores das disciplinas e a docente júnior que aplicou as atividades em período inverso das aulas. Os acadêmicos envolveram-se com seus próprios modelos mentais como motivação para interpretações e análises na perspectiva da matemática significativa.

As atividades foram elaboradas com o propósito de que os acadêmicos as realizassem de forma independente e, também, colaborativa. A temática abordada referese às questões cotidianas, como o jato d'água de uma mangueira de incêndio, consumo de combustível de um carro e velocidade de uma pedra ao ser arremessada, essas mesmo consideradas simples, tornaram-se possíveis de serem utilizadas de conhecimentos prévios para a construção de novos conceitos matemáticos aliados à física e ao cálculo. Ao desenvolver habilidades com a ferramenta descrita, pela articulação entre as atividades propostas, também promoveu a interação entre acadêmicos, docente Júnior e professor.

\section{Sequência de atividades}

Ressalta-se, aqui, que a proposta visa a utilização das ferramentas tecnológicas, bem como o material (caderno e lápis) para organização dos dados para a resolução de situações problemas. Essas, visam compreender relações entre alguns tipos de funções do primeiro e segundo graus e as características de seus gráficos como forma de trabalhar os conceitos de Física e Matemática. A resolução está apoiada pelos recursos do software Mathcad Prime para posterior análise.

Após essas considerações, foram tratadas situações problemas utilizando-se de recursos tecnológicos a fim de avaliar o tratamento dos dados nos sistemas e verificar a contribuição dos mesmos no viés da aprendizagem significativa. É importante considerar que essas atividades foram propostas concomitantemente com as disciplinas de Fundamentos de Matemática “A”, Cálculo Diferencial e Integral I e Física Geral "A”, cursadas pelos acadêmicos.

Atividade 1: Tema abordado no componente curricular de Fundamentos de Matemática A - Análise do ponto de Equilíbrio.

Certa marca de Picapes com motor Flex custa $\mathrm{R} \$ 72.350,00$ e com motor a diesel custa $\mathrm{R} \$ 105.290,00$. Os números de quilômetros por litro de combustível para 
carros com esses dois motores são 8,2km/l e 15,2km/l, respectivamente. Suponha que o preço da gasolina seja de $\mathrm{R} \$ 3,98$ por litro e do diesel seja de $\mathrm{R}$ \$2,57 por litro. Assim sendo, o custo $\mathrm{C}_{\mathrm{g}}(\mathrm{x})$ de um carro a gasolina, ao percorrer $\mathrm{x}$ quilômetros, é $\mathrm{C}_{\mathrm{g}}(\mathrm{x})=72.350,00+\frac{3,98}{8,2} \mathrm{x}$ e o custo $\mathrm{C}_{\mathrm{d}}(\mathrm{x})$ de um carro a diesel, ao percorrer $\mathrm{x}$ quilômetros, é $C_{d}(x)=105.290,00+\frac{2,57}{15,2} x$, então o ponto de equilíbrio, ou seja, a quilometragem à qual o carro a diesel se torna mais econômico do que o carro a gasolina é?

Os questionamentos foram feitos a partir da leitura da atividade. O aluno A disse: "posso dar valor para a quilometragem em ambas as funções e verificar onde se igualam”. E assim o fez, como na Figura 2.

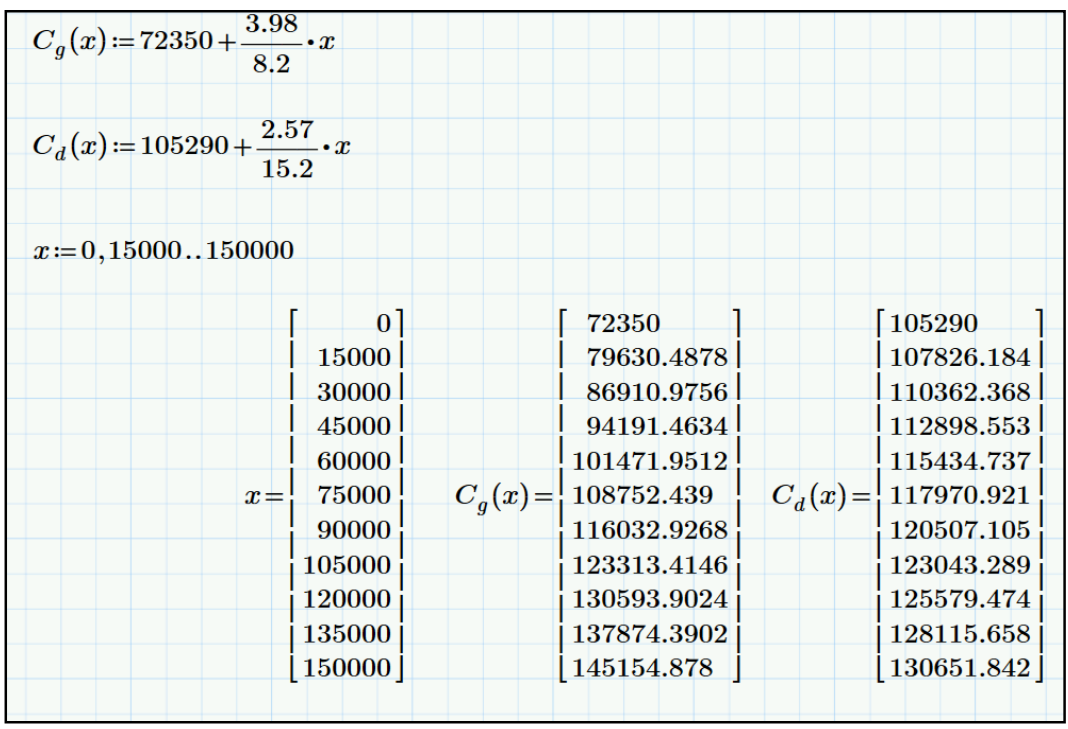

Figura 2: Resolução pelo Mathcad Prime 3.1

Fonte: Autores

Observando o resultado, constataram que a quilometragem entre 105000 e 120000 representa o intervalo no qual se situa o ponto de equilíbrio, pois nesse intervalo $C g(x)=123313.4146$ se aproxima de $C d(x)=123043.289$. $O$ aluno A propôs atribuir outros valores nesse intervalo a fim de verificar o valor da quilometragem. Representação do desenvolvimento na Fig. 3.

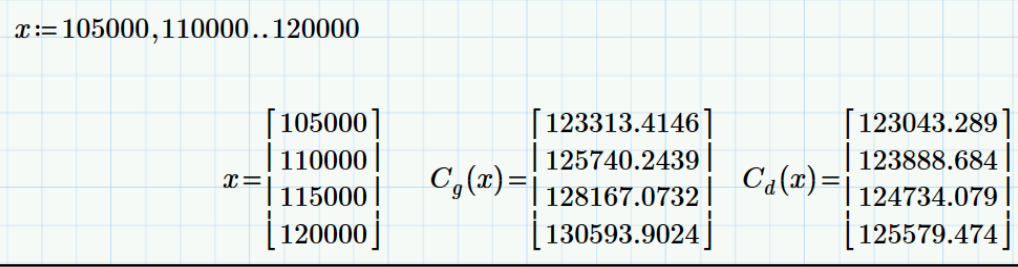


Figura 3: Representação do desenvolvimento no Mathcad Prime 3.1

Fonte: Autores

Já o aluno B, propôs que se igualassem as equações, pois observou que em uma dada quilometragem o custo seria o mesmo tanto para o carro quanto para a picape. Então, pela ferramenta solve disponibilizada pelo software para resolver uma equação, tem-se na Fig. 4:

$$
\begin{aligned}
& C_{g}(x):=72350+\frac{3.98}{8.2} \cdot x \quad C_{d}(x):=105290+\frac{2.57}{15.2} \cdot x \\
& C_{g}(x)=C_{d}(x) \\
& 72350+\frac{3.98}{8.2} \cdot x=105290+\frac{2.57}{15.2} \cdot x \stackrel{\text { solve }}{\longrightarrow} 104145.94896250824413
\end{aligned}
$$

Figura 4: Resolução algébrica pelo Mathcad Prime 3.1

Fonte: Autores

Para que visualizassem tal situação, a construção do gráfico foi proposta, conforme Fig. 5.

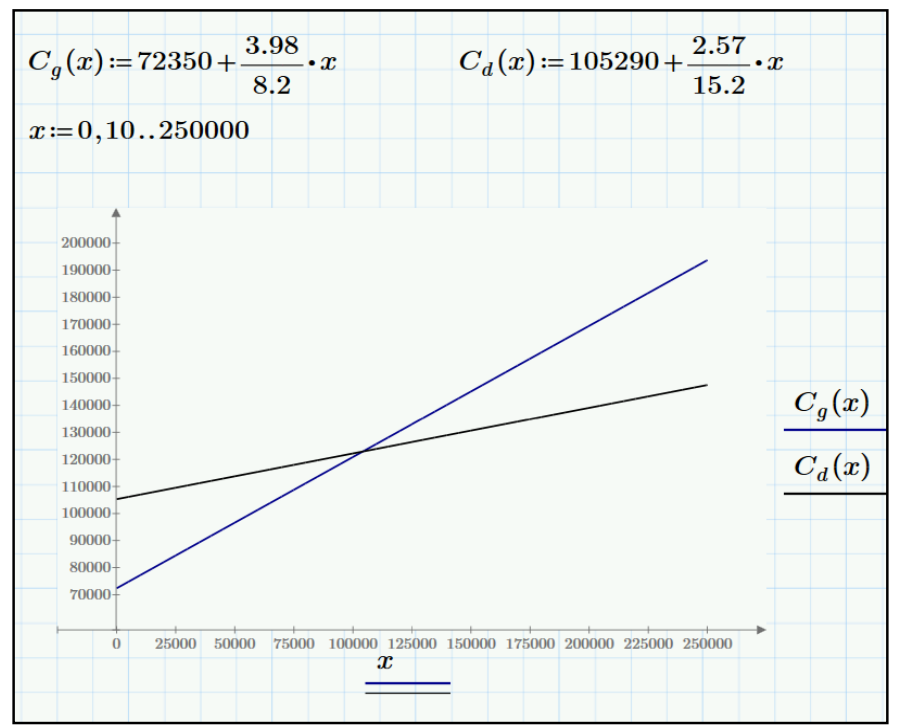

Figura 5: Representação algébrica e gráfica

Fonte: Autores

Depois de finalizada a tarefa, observou-se que os valores das quilometragens por litro estavam desatualizados. Então, questionou-se sobre a possibilidade de ajustá-los. Dessa forma, os acadêmicos alteraram os valores e por tratar-se de um recurso dinâmico, o mesmo gerou automaticamente os resultados.

Os acadêmicos perceberam que o recurso possibilita atribuir dados de entrada com valores para variáveis, bem como definir funções. As funções são declaradas e permitem serem chamadas e utilizadas tanto para a atribuição de valores numéricos 
como para a plotagem dos gráficos. A representação gráfica torna visível os intervalos de crescimento, decrescimento e a intersecção de ambas as retas situando o ponto de equilíbrio.

Atividade 2: Tema abordado no componente curricular de Cálculo Diferencial e Integral I - Movimento de um projétil na lua.

Uma pedra atirada verticalmente para cima a partir da superfície da Lua com velocidade de $24 \mathrm{~m} / \mathrm{s}$ (em torno de $86 \mathrm{~km} / \mathrm{h}$ ) atinge uma altura de $\mathrm{s}(\mathrm{t})=24 \mathrm{t}-0,8 \mathrm{t}^{2}$ metros em t segundos. Pergunta-se: a) A velocidade e a aceleração da pedra no instante t são dadas por?; $b$ ) o tempo t em que a pedra leva para atingir o ponto mais alto e a altura máxima atingida?; $c$ ) quanto tempo a pedra ficará no ar?; $d$ ) quanto tempo à pedra levará para atingir a metade de sua altura máxima?

Depois que o professor indagou aos acadêmicos sobre o que representa a função $s(t)$, a qual descreve a posição de um objeto em movimento no instante t, também fez-se o mesmo questionamento aos alunos sobre as aplicações do cálculo, sua derivada s'(t), que fornece a taxa de variação instantânea do movimento, ou seja, a velocidade deste objeto no instante t. Já a segunda derivada de $s(t)$, s"'(t) fornece a taxa de variação instantânea de s'(t), ou seja, a taxa de variação da velocidade, é conhecida como aceleração instantânea. Se $s$ "' $(t)>0$, o objeto está acelerado e se $s$ '” $(t)<0$, o objeto está desacelerado.

Essas conclusões foram estabelecidas de acordo com as respostas oriundas dos acadêmicos conforme seus conhecimentos prévios.

a) a velocidade e a aceleração da pedra no instante $t$ são dadas por? A resolução realizada pelo aluno C está representada na Fig. 6.

$s(t):=24 t-0.8 t^{2}$
Como a velocidade é dada pela variação de $s$ em função de $t$, ou seja, calcula-se a
derivada da função s em relação a t:
$v(t):=\frac{\mathrm{d}}{\mathrm{d} t} s(t) \rightarrow-1.6 \cdot t+24$
Como a aceleração é dada pela variação de $v$ em função de $\mathrm{t}:$
$a(t):=\frac{\mathrm{d}}{\mathrm{d} t} v(t) \rightarrow-1.6 \quad a(t):=-1.6 \frac{\mathrm{m}}{\mathrm{s}^{2}}$

Figura 6: Resolução algébrica Fonte: Autores

b) o tempo t em que a pedra leva para atingir o ponto mais alto e a altura máxima atingida? 
A resolução e representação gráfica referente à atividade 2 apresentada pelo aluno C pode ser visualizada na Fig. 7.

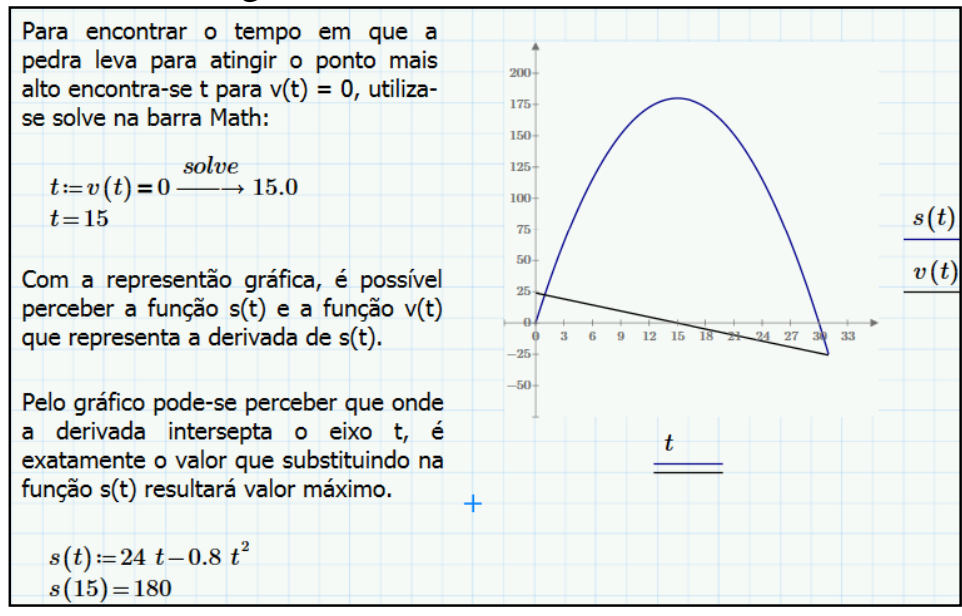

Figura 7: Representação gráfica da atividade 2 Fonte: Autores

c) quanto tempo a pedra ficará no ar? Sabendo que para atingir o ponto mais alto a pedra leva 15s. "Então para chegar ao chão ela levará novamente 15s. Com isso, a pedra ficará no ar 30s", disse o aluno C.

d) quanto tempo a pedra levará para atingir a metade de sua altura máxima?

Resolução representada na Fig. 8.

$$
s(t)=\frac{s(15)}{2} \stackrel{\text { solve }}{\longrightarrow}\left[\begin{array}{c}
4.393398282201787134 \\
25.606601717798212866
\end{array}\right]
$$

Figura 8: Representação algébrica

Fonte: Autores

Nessa atividade, verificou-se que os acadêmicos apresentavam conhecimentos prévios e ritmos de aprendizagem diferentes.

$O$ recurso do software possibilitou uma economia de tempo para a resolução das operações matemáticas, bem como na construção gráfica. Por tratar-se de um problema simples, junto a linguagem matemática e capacidade de abstração desses elementos, bem como a visualização gráfica, os acadêmicos correlacionaram com outras situações problemas em outras áreas do conhecimento, como os relacionados as ciências exatas e da terra; engenharias e ciência da computação e ainda a seus campos de atuação.

A interface do programa e suas funções residentes, que propiciaram representações tornou possível por meio da atividade ressignificar/reconstruir o conceito de velocidade e aceleração vistas em física conectados com o conceito de derivada e função quadrática.

Atividade 3: Tema abordado no componente curricular de Física Geral A - 
Aplicação física de derivada:

Desprezando a resistência do ar, o jato d'água de uma mangueira de incêndio satisfaz à equação $y(x)=m x-16 .\left(1+m^{2}\right) \cdot\left(\frac{x}{v}\right)^{2}$, onde m é a inclinação do bico, v é a velocidade do jato no bico, em metros por segundo, e y é a altura em metros do jato a $\mathrm{x}$ metros do bico (Fig.9). Considere que v seja uma constante positiva. Calcule:

(a) o valor de x para o qual a altura y do jato seja máxima para um valor fixo m;

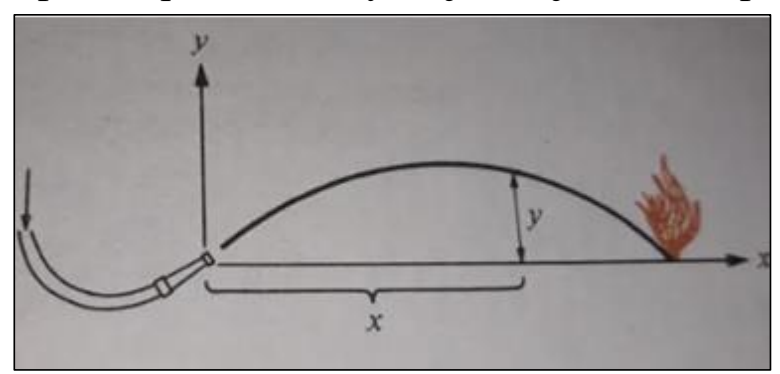

Figura 9: Jato d'água de uma mangueira de incêndio Fonte: Munem e Foulis (1982, p. 189)

A resolução referente à atividade 3, letra a, está representada na Fig. 10.

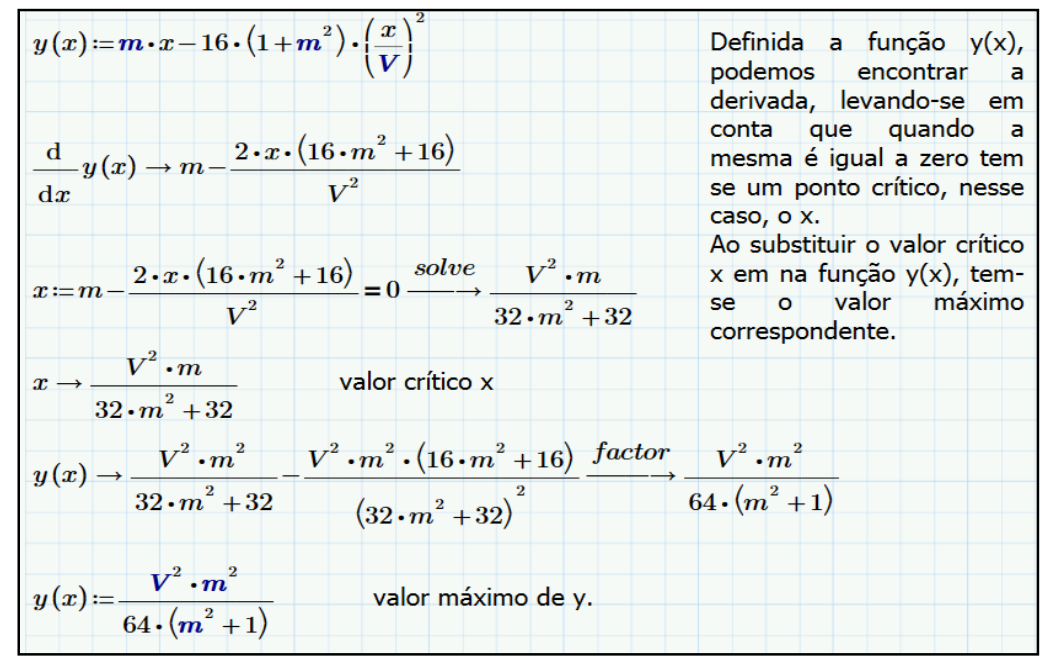

Figura 10: Resolução algébrica da letra a Fonte: Autores

b) o valor de m para que o jato chegue ao chão a uma distância máxima do bico; A resolução referente à atividade 3 , letra b, está representada na Fig. 11 . 


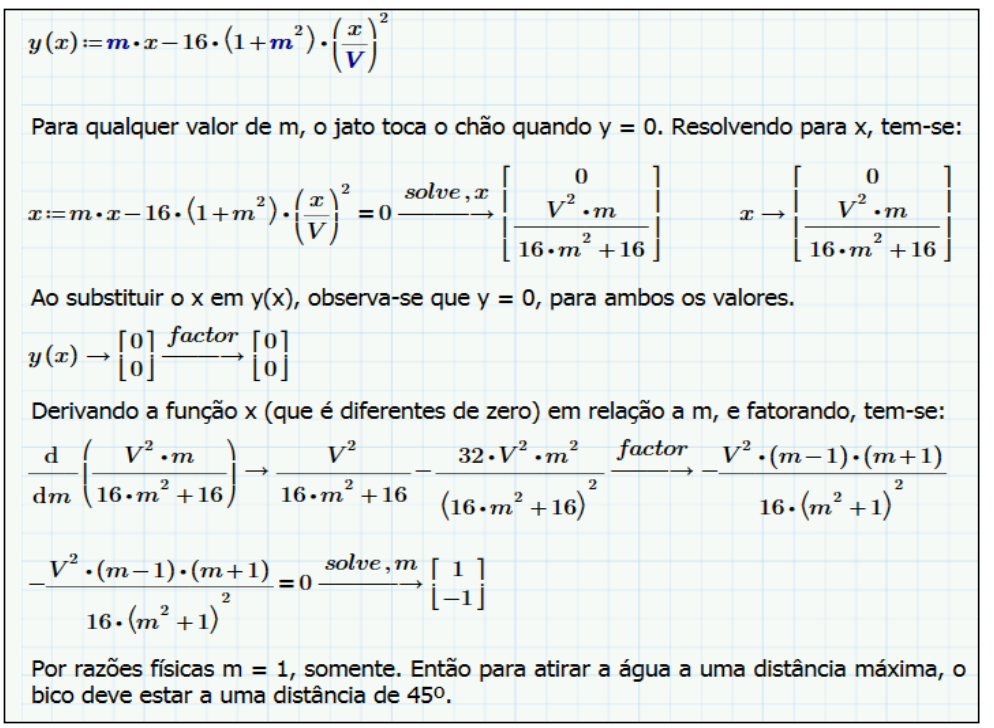

Figura 11: Resolução algébrica da letra b Fonte: Autores

Ao discutir e resolver essa situação, os acadêmicos concluíram que precisavam definir quais letras eram variáveis e quais delas eram constantes. Observaram que poderiam dar valores numéricos as constantes ou variáveis e determinar outras situações e até mesmo representações gráficas com a base oferecida no problema, como, por exemplo, encontrar ainda o valor de m para qual a água vai atingir altura máxima num muro vertical a x metros do bico da mangueira. Observaram o potencial de generalização da ferramenta e desenvolvimento da capacidade matemática pela interface que contempla seus elementos específicos dando condições de análise, experimentação e validação.

\section{Análise das atividades desenvolvidas}

Ao avaliar o uso do software Mathcad Prime, que teve por finalidade didática o desenvolvimento das atividades envolvendo as situações problemas que abordam aplicações que envolvem funções, cálculo diferencial e integral como ferramentas para serem utilizados em diferentes ramos acadêmicos, observou-se a boa aceitação do mesmo pelos acadêmicos. Eles consideraram o ambiente motivador, em que a interação entre o objeto de estudo e o recurso permitiram que eles tomassem a iniciativa e controle de sua ação de estudar e de aprender.

Embora não se tenha apresentado conceitos novos pelas atividades desenvolvidas, 
pode-se perceber que a ferramenta possibilita a criação de subsunsores ${ }^{5}$ incidindo num melhor domínio e apreensão de conceitos que envolvem o cálculo e a física. No entanto, se forem oferecidas novas situações problemas são capazes de desenvolver, estruturar, abstrair e aplicar esses conhecimentos constituindo novos conceitos pela manipulação e análise desses, fato esse constatado pelos professores das disciplinas de Fundamentos de Matemática “A”, Cálculo Diferencial e Integral I e Física Geral “A”, na sala de aula com a sequência em seus conteúdos programáticos.

Ao ser manipulado, o Mathcad interpreta um documento seguindo o princípio da leitura (da esquerda para a direita e de cima para baixo). Uma vez descrita equações numéricas ou definidas variáveis e funções simbólicas, estará disponível para ser usada em qualquer lugar a seguir no documento, proporcionando avaliar modificações sobre o objeto de estudo de forma prática e dinâmica, conforme apresentado na Fig. 1. O tempo para o cálculo fica reduzido, sendo então desprendido para análise do processo de desenvolvimento e de aprendizagem, colaborando para a transposição do conhecimento prévio para uma nova situação. Por apresentar uma interface que dispõe de elementos de texto e cálculo, cada acadêmico na sua individualidade pôde fazer as representações e comentários, indicando as estratégias e os métodos que utilizou para encontrar a solução do problema, bem como sua análise de solução. Ao cometer algum tipo de erro, por exemplo, a não definição de uma variável, a ferramenta aponta uma mensagem, colaborando assim para trabalhar dificuldades.

Além disso, foi possível perceber que ao realizar experimentações para a resolução das atividades propostas, os acadêmicos, de forma autônoma e/ou colaborativa, utilizaram diversos procedimentos de raciocínio, como o lógico, abstrato, ressaltando as potencialidades cognitivas que esse recurso pode despertar, melhorando suas condições de aprendizagem.

Com a abordagem intuitiva dos conceitos contidos no ambiente, enfrentou-se as condições de manipulação e dinamicidade que a tecnologia ofereceu promovendo a mudança da postura do acadêmico frente a sua utilização, pois também evidenciaram críticas, como por exemplo, quanto a formatação de resultados, no que se refere ao número de casas decimais não poder ser limitado. O potencial das múltiplas representações em caráter dinâmico, com as manipulações diretas, tornou possível o estabelecimento de relações e propriedades do objeto de estudo. Provocaram-se reflexos

\footnotetext{
5 A aprendizagem significativa ocorre quando a nova informação ancora-se em conceitos relevantes (subsunçores) preexistentes na estrutura cognitiva do aprendiz Ausubel (2003).
} 
nos processos cognitivos, pois se levantou conjecturas baseadas na matemática.

Ao considerar os estágios de desenvolvimento das habilidades matemáticas dos acadêmicos e a caracterização das atividades com o aumento do grau de complexidade, pode-se perceber a compreensão dos conteúdos por parte dos alunos com significação, influenciadas pelas diferentes formas de construção dos conteúdos matemáticos proporcionada pelo software. Nessa perspectiva, a aprendizagem significativa com apoio das tecnologias na educação recria ambientes que permitem ao acadêmico entender o que ele faz, propor desafios e auxiliá-lo a atribuir sentido e significado ao que está realizando no papel.

\section{Conclusão}

Com a abordagem e desenvolvimento das atividades propostas e o apoio das tecnologias, pode-se promover a conexão com o que já foi aprendido, compondo assim novos significados. Com a correlação da bagagem dos conceitos dos alunos e a potencialização por meio de artifícios pedagógicos, foi possível dar sentido aos novos assuntos abordados. Essa relação direta e a interação entre os envolvidos nesse processo proporcionou aprendizagem colaborativa.

O grupo de acadêmicos que participou das atividades tinham como objetivo estudar o que antes era memorizado, exigindo dos mesmos empenho para integrar o conhecimento novo ao já existente, onde as informações aprendidas significativamente por meio das ferramentas utilizadas como apoio ao ensino, foram aplicadas em uma variedade de problemas, desenvolvendo, assim, habilidades de aplicação desses em outros contextos, potencializando a análise e a geração de hipóteses, o que caracteriza a aprendizagem significativa.

A preocupação em potencializar a capacidade dos acadêmicos na Universidade, fez com que fosse desenvolvida essa atividade de acompanhamento pedagógico. E essa experiência conduziu a outros questionamentos e ações em busca de práticas para um ensino mais significativo. Embora o processo que envolve o ensino e a aprendizagem seja bastante complexo, é necessário experimentar. Dessa forma, a partir da prática e considerações apresentadas, pode-se perceber que a tecnologia pode conectar diferentes áreas do conhecimento, estabelecendo assim um maior número de relações interdisciplinares com o objeto de estudo.

É importante salientar que não se quer destacar uma metodologia ou método como 
"um mais adequado que outro", e sim o que melhor se adapte as necessidades e características da turma. Considera-se aqui que o uso do recurso do software Matemático foi o ponto de partida para o desenvolvimento de outras situações didáticas desencadeadas de momentos de reflexão.

Podem ser citadas como exemplo duas situações: 1) ao observar a necessidade de acompanhar o "tempo de cada acadêmico", respeitando as individualidades de cada um, e conhecimentos prévios na disciplina de Cálculo Diferencial e Integral V, utilizou-se da estratégia da Sala de Aula Invertida ${ }^{6}$, onde em algum momento propôs-se os conteúdos e as instruções online, e ao retornarem para a sala de aula eram realizadas outras atividades mais práticas, como a resolução de problemas. 2) ao ministrar a disciplina de Cálculo Numérico Computacional, estabeleceu-se parcerias na pesquisa e no desenvolvimento de experiências de aprendizagem.

No que tange à pesquisa, houve interesse de um acadêmico em dinamizar e automatizar os cálculos referentes aos métodos numéricos utilizados na resolução de problemas reais, convergindo para o desenvolvimento de um projeto de iniciação científica. E como forma de alargar a significação de conceitos, buscou-se junto a outros componentes curriculares estabelecer conexões interdisciplinares no afã de aplicar esses métodos em problemas reais aos quais envolveram questões como as relacionadas à engenharia econômica, reações químicas e a sistemas de energia, conectando, assim, as áreas do conhecimento.

As práticas pedagógicas do professor são de fato importantes para o desenvolvimento da capacidade do acadêmico em utilizar conhecimentos em novos contextos e em diferentes situações. O uso do software Mathcad como mediador pode estabelecer uma relação direta entre conhecimento prévio e o novo, determinando-se como um recurso que institui possibilidades e potencialidades imprescindíveis para o desenvolvimento da representação mental do acadêmico, em que essas representações envolvem desde identificação de regras, relações conceituais e a utilização de modelos que se ajustam às situações reais.

Em linhas gerais, ressalta-se que o processo educacional deve ser permanente e a tecnologia pode promover diferentes abordagens. Aliando-se prática e reflexão tem-se uma educação com qualidade com vistas a formar profissionais competentes e

\footnotetext{
${ }^{6}$ Como uma técnica educacional que consiste em duas partes: atividades de aprendizagem interativas em grupo em sala de aula e orientação individual baseada em computador fora da sala de aula (BISHOP; VERLEGER, 2013 apud PAVANELO; LIMA, 2017).
} 
comprometidos com a comunidade.

\section{Referências}

ANJOS, A. J. S., NOVAK, J. D., HANESIAN, H. As equações matemáticas no ensino de Física: Uma análise de conteúdos em livros didáticos de Física. Revista Electrónica de Enseñanza de las Ciencias, s.1., v. 14, n. 3, p. 312-325, 2015.

AUSUBEL, D. P., NOVAK, J. D. e HANESIAN, H. Psicologia educacional. Tradução de Eva Nick. RJ: Editora Interamericana Ltda.1980.

AUSUBEL, D. P. Aquisição e Retenção de Conhecimentos: Uma Perspectiva Cognitiva. Lisboa: Plátano, 2003.

BRASIL. Secretaria da educação Básica. Orientações Curriculares para o Ensino Médio: Ciências da Natureza, Matemática e suas Tecnologias. Brasília, MEC, 2006.

COSTA, F. A. (Ed.). Repensar as TIC na educação: o professor como agente transformador. Carnaxide: Santilhana, 2012.

FINK, L. D. Creating Significant Learning experiences: an integrate approach to designing college courses. San Francisco: Jossey- Bass. 2003.

IMBERNÓN, F. Inovar o ensino e aprendizagem na Universidade. 40 ed. São Paulo: Cortez, 2012.

MATHCAD PRIME. "PTC Mathcad. PTC", 2009. Disponível em $<$ https://www.mines.edu/ccit/software-title/mathcad/>. Acesso em: 21 jul. 2018.

MOREIRA, M. A. A teoria da aprendizagem significativa e sua implementação na sala de aula. Brasília: Editora Universidade de Brasília, 2006.

PAVANELO, E.; LIMA, R. Sala de Aula Invertida: a análise de uma experiência na disciplina de Cálculo I. Bolema, Rio Claro (SP), v. 31, n. 58, p. 739-759, ago. 2017.

RETZLAFF, E., PRESTES, R. F., COSTA, M. A., MANTTAI, R. D., SOARES, E. G., FRANZIN, R. F. Melhoria do sistema ask math para o incentivo à metodologia da resolução de problemas. ENEM. SP, 13 a 16 de julho de 2016.

RODRIGUES, C. R. Ensino de Física nas Séries Iniciais: Um Estudo de Caso sobre Formação Docente. Caderno Brasileiro do Ensino de Física, s.1, v. 26, n. 3, p. 575608, dez. 2009.

SANTOS, R., LORETO, A. B., GONÇALVES, J. L. Avaliação de softwares matemáticos quanto a sua funcionalidade e tipo de licença para uso em sala de aula. REnCiMa-Revista Ensino de Ciências e Matemática, s.l., v. 1, n. 1, p. 47-65, 2010.

SCHEID, N. M. J. Construção Coletiva de Conhecimentos na Pesquisa em Educação nas Ciências. Revista Pesquisa Qualitativa, São Paulo (SP), v.5, n.9, p. 452-465, dez. 2017. 
TARDIF, M. Saberes docentes e formação profissional. Petrópolis, R.J: Editora Vozes, 2002.

Recebido em: 09 de julho de 2018.

Aceito em: 25 de julho de 2018. 